$\checkmark$ he claims that there is "no reason to suppose" that this trend "could not generate the same kind of revolutionary discoveries in the future".

One wonders. Simple apparatus was perfectly suited for picking what (fairly or not) now looks like the low-hanging fruit of science - and there was a vast garden of fundamental discoveries, from microorganisms to the laws of motion, to be picked. I have had the impression over the years that some historians of science dislike using the word 'progress' for fear of implying that all history was building towards the modern age. But although human history is under no obligation to make or demonstrate progress (by whatever measure), science is explicitly designed for it. My fruit-picking reference might make me sound like a pillager of the environment, out of tune with modern sensibilities, but that's a problem with our metaphors, not with our reality.

Science really does build on its history, those shoulders of giants and bricks of knowledge. That's its point. And as a working scientist myself, I can't help but believe that our knowledge becomes more complex, refined and complete as time goes on. We $\begin{array}{ll}\text { "Realityseems } & \text { revise, we reassess, } \\ \text { increasingly } & \text { we revisit - but } \\ \text { complicated } & \text { always in the inter- } \\ \text { aswe malke } & \text { our ideas against } \\ \text { better } & \text { physical reality. } \\ \text { measurements } & \text { And although that } \\ \text { of it." } & \text { reality also seems } \\ & \text { increasingly com- }\end{array}$ plicated as we make better measurements of it, that forces our theories and experiments to keep pace. All too often, it forces our equipment and funding to keep pace, as well.

I grew up in a small farming town, and know exactly what it's like to be passionately interested in science, making do without many of the resources needed to explore it. If I saw some unusual creature under my microscope, no one could tell me what it was. I would have loved to have seen Comet West when it passed through the inner Solar System in 1976, but the local newspapers never mentioned it. I am very sympathetic to 'makers' and basement experimenters. But no matter how appealing the prospect might be, I think that the chances of revolutionary experiments happening with simple materials are dwindling by the year.

Derek Lowe has worked in early-stage drug discovery for decades. He writes In the Pipeline, one of the world's longestrunning science blogs.

e-mail:derekb.lowe@gmail.com

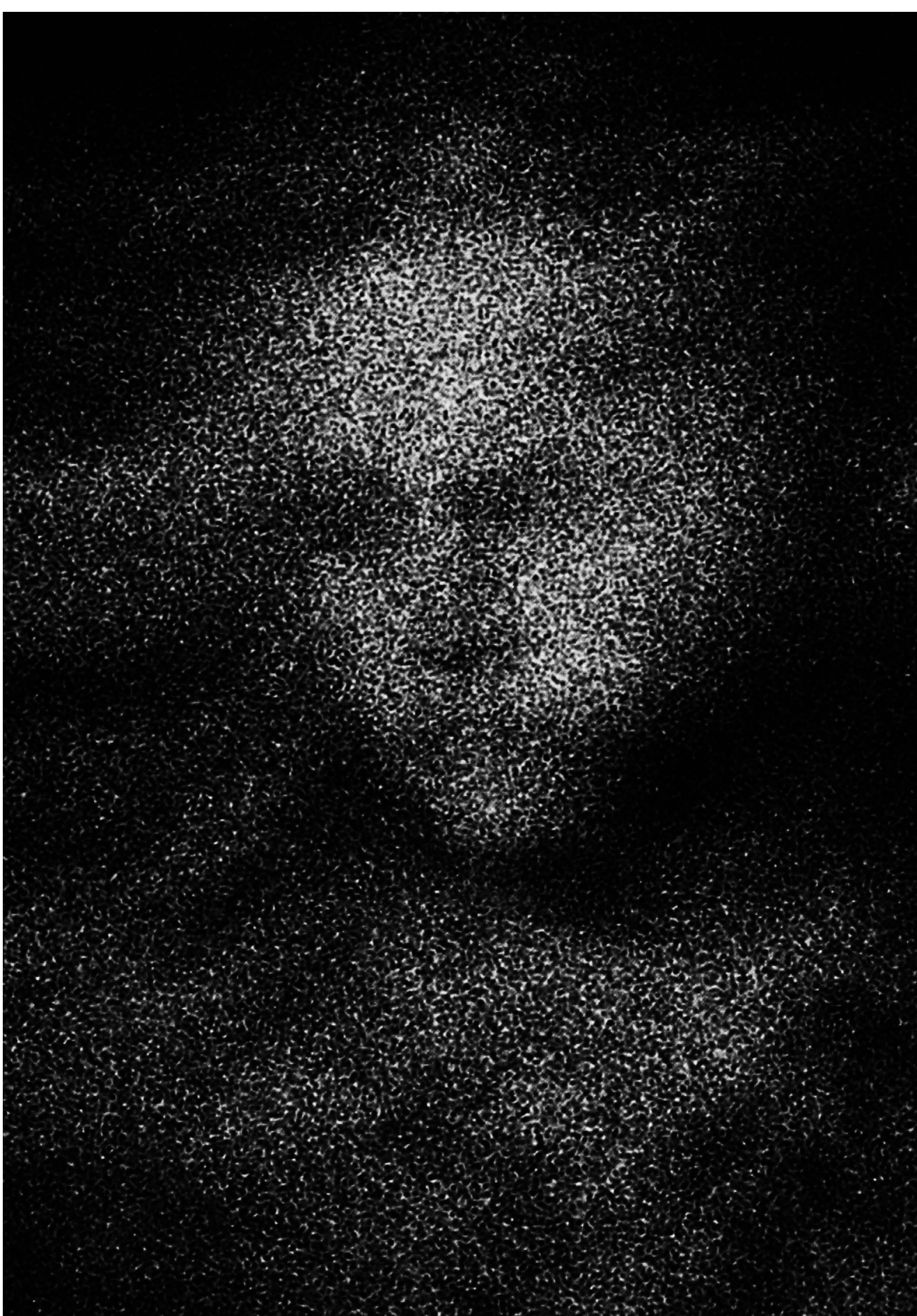

No. 348. Candid Portrait of a Woman on a Street Corner by Trent Parke (2013).

\section{EVOLUTIONARY PSYCHIATRY}

Foundations of mental illness 
$\mathrm{G}^{\mathrm{s}}$ lobally, the burden of depression and other mental-health conditions is on the rise. In North America and Europe alone, mental illness accounts for up to $40 \%$ of all years lost to disability. And molecular medicine, which has seen huge success in treating diseases such as cancer, has failed to stem the tide. Into that alarming context enters the thought-provoking Good Reasons for Bad Feelings, in which evolutionary psychiatrist Randolph Nesse offers insights that radically reframe psychiatric conditions.

In his view, the roots of mental illnesses, such as anxiety and depression, lie in essential functions that evolved as building blocks of adaptive behavioural and cognitive function. Furthermore, like the legs of thoroughbred racehorses - selected for length, but tending towards weakness - some dysfunctional aspects of mental function might have originated with selection for unrelated traits, such as cognitive capacity. Intrinsic vulnerabilities in the human mind could be a trade-off for optimizing unrelated features.

Similar ideas have surfaced before, in different contexts. Evolutionary biologists Stephen Jay Gould and Richard Lewontin, for example, critically examined the blind faith of 'adaptationist' evolutionary theorizing. Their classic 1979 paper 'The spandrels of San Marco and the Panglossian paradigm' challenged the idea that every aspect of an organism has been perfected by natural selection (S. J. Gould et al. Proc. R. Soc. Lond. B 205, 581-598; 1979). Instead, like the curved triangles of masonry between arches supporting domes in medieval and Renaissance architecture, some parts are contingent structural by-products. These might have no discernible adaptive advantage, or might even be maladaptive. Gould and Lewontin's intuition has, to some extent, been vindicated by molecular genetics. Certain versions of the primitive immune-system protein complement $4 \mathrm{~A}$, for instance, evolved for reasons unrelated to mental function, and yet are associated with an increased risk of schizophrenia.

\section{GENETIC TRADE-OFFS}

Decades earlier, the evolutionary theorist $\sum$ George C. Williams explored perhaps the most perplexing aspect of human biology: our inconvenient tendency to age and die. He suggested in 1957 that some of the genes that cause ageing evolved

because they enhanced fitness early in life (G. C. Williams Evolution 11, 398-411; 1957). Such 'antagonistic pleiotropy' - in which a single gene controls at least one beneficial and one detrimental trait suggests that the design of biological structures is a complex optimization problem involving multiple trade-offs. Emotions and other aspects of mental function are

not like machine components, each with a set function; instead, they are embedded in complex overlapping biochemical pathways.

In 1994, Nesse teamed up with Williams for Why We Get Sick, a manifesto for "Darwinian medicine". Their insights opened up new perspectives on the origins of diseases, arguing for 'proximate' causes (driven by anatomy, biochemistry and physiology) and higher-level 'ultimate' (evolutionary) causes. They noted that evolution selects for reproductive success rather than for health and happiness; hence, the existence of human diseases and disorders. They also detailed the contingent and sometimes 'irrational' nature of biological legacies, such as the nerves and blood vessels that run across the human eye's retinal surface. Cephalopod eyes don't have this 'flaw'.

Good Reasons for Bad Feelings builds on these insights. Adopting an "engineers' point of view" on mental illnesses, Nesse suggests that anxiety, although apparently undesirable, is a design component with utility in certain situations - for instance, as a "smoke detector" for potentially life-threatening events. Depression might also perform adaptive functions. The psychiatrist Aubrey Lewis argued that by signalling distress, depression could prompt others into providing assistance through foraging and other activities. It has even been suggested that depressive behaviour in vervet monkeys (Chlorocebus pygerythrus) evolved to signal loss of status, deflecting attacks from dominant males.

Yet, however functional its components when appropriately regulated, mental illnesses cause suffering, and evidence-based treatments are sparse. Indeed, the field

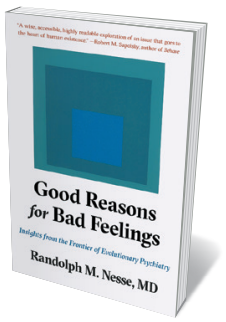

Good Reasons for Bad Feelings: Insights From the Frontier of Evolutionary Psychiatry RANDOLPH M. NESSE Dutton (2019) has seen no significant pharmaceutical breakthroughs for many years. Biological causes remain elusive, and biomarkers non-existent.

Psychiatry as a field, meanwhile, quivers with theoretical uncertainty. It has not become a sub-speciality of neurology, as one might have expected if mental illness mapped directly to neural behaviour. And common genetic variations with large effects on mental disorders are elusive. The various incarnations of the American Psychiatric Association's Diagnostic and Statistical Manual of Mental Disorders (DSM) have enabled diagnostic consistency and the objectification of mental illnesses. But the DSM has resulted in overlapping diagnoses, and contrived symptom-cluster checklists. At times, it impinges on the territory of healthy mental function. Allen Frances, chair of the task force that wrote the manual's fourth edition in 1994, revolted against out-ofcontrol mental diagnosis in his 2013 book DSM: Saving Normal.

\section{FROM ADAPTIVE TO MALADAPTIVE}

Nesse argues that evolutionary theory could foster therapeutic breakthroughs by providing a robust theoretical foundation for psychiatry. He posits that it might also help to prevent people from equating psychiatric symptoms with diseases and viewing extremes of emotion such as anxiety as disorders. Nesse also suggests that mental illnesses might result from the disruption of regulators that maintain equilibrium in the body, such as the endocrine system. The normally adaptive function of thoughts and emotions could, in such instances, become maladaptive.

The future success of clinical psychiatry might depend on an evolutionary framework being integrated with whole-genome sequence-data analysis; this could help to identify mutations predisposing people to mental illness. Given the small contributions of individual genes and the diverse mechanisms involved, this will demand analysis of the genomes of hundreds of thousands of people. As a result of the extensive and often paradoxical entanglement of genetic networks, future treatments might, by necessity, require mental circuits to be engineered to release them from hard-wired evolutionary constraints.

In Theodicy (1710), German philosopher Gottfried Leibniz argued that God, being omniscient, must have created the best of all possible worlds. (Fifty years later, in his novel Candide, Voltaire lampooned Leibniz as Doctor Pangloss, who opined that faults in the world are necessary, like contrasting shadows in a painting.)

Ironic readings aside, the philosopher's optimism might now be shown to have rational echoes in contemporary science. As Good Reasons for Bad Feelings boldly posits, many of the core dysfunctional components of mental illness ultimately help to make us human.

Adrian Woolfson is the author of Life Without Genes.

e-mail: adrianwoolfson@yahoo.com 